\title{
Argon laser trabeculoplasty in exfoliation syndrome
}

\author{
MARK B SHERWOOD AND BJORN SVEDBERGH \\ From Moorfields Eye Hospital, High Holborn, London WC1V 2AN, and University Hospital, \\ Uppsala, Sweden
}

SUMmARY A retrospective study of the effects of argon laser trabeculoplasty on a consecutive series of 44 phakic patients (55 eyes) with exfoliation syndrome glaucoma is reported. The followup was 12 to 23 months, mean 15 months. At an individual level laser trabeculoplasty was successful in $70 \%$ of the patients and $40 \%$ were able to reduce or stop their medication. Two patients showed 'late failure' at 15 months after initial control. An early rise of intraocular pressure was fairly common in the exfoliation group, and perhaps these patients need particularly careful monitoring during the initial hours following argon laser trabeculoplasty. A beneficial effect was noted on diurnal curve fluctuations and peak intraocular pressures.

Several investigators have shown that argon laser trabeculoplasty (ALT) is an effective method of treatment in many patients with exfoliation syndrome glaucoma. ${ }^{1-3}$ It has been noted that the prognosis of exfoliation glaucoma patients treated either medically and/or surgically is poorer than that of simplex glaucoma patients. ${ }^{45}$

This study retrospectively considers the results of ALT performed in 1982 at the University Hospital, Uppsala, on phakic patients with exfoliation syndrome glaucoma.

\section{Materials and methods}

A consecutive series of 44 phakic patients (55 eyes) with exfoliation syndrome were studied who received argon laser trabeculoplasty between January and December 1982. This allowed for a 12- to 24-month follow-up for each patient. Four cases with previous filtering surgery to the eye concerned were excluded.

Prior to laser treatment the patients were admitted to hospital and a diurnal pressure curve consisting of seven readings, performed with a Goldmann applanation tonometer, was plotted. Laser trabeculoplasty was performed by a coherent system argon laser, Lasertek $40 \mathrm{~A}$, to $180^{\circ}$ of the trabecular meshwork at a sitting (except two patients who received $90^{\circ}$ laser therapy per session), with the number of burns varying from 23 to 60 (mean 40 ) to each half of the angle meshwork. A $50 \mu \mathrm{m}$ spot size and $0 \cdot 1$ second time exposure was used (except one case

Correspondence to Mr M B Sherwood, FRCS. where $0 \cdot 2$ second was employed), and the power was adjusted to obtain a suitable end point for the individual. Seven different surgeons carried out the laser treatment of these patients.

After laser treatment the intraocular pressures were measured on the patients in hospital to detect any early pressure rise, and some patients were started on corticosteroid drops.

Subsequent pressure measurements were taken at various intervals, with the patient either in hospital, in which case a diurnal curve of seven readings were plotted, or as an outpatient, when either a single set of readings or three readings spread over a morning and afternoon were recorded. Only 11 eyes had diurnal curves plotted for more than six months after the laser therapy.

It was decided that the criteria used to judge 'success' of laser treatment in a given case would be two-fold, namely (1) an average fall in mean intraocular pressure of at least $20 \%$ from the baseline value; (2) in addition, no two consecutive intraocular pressures above $21 \mathrm{mmHg}$.

Two patients who by these criteria would be judged successful cases were excluded when classification into success or failure was considered, because their medication was increased between one and nine months after laser treatment. In one case of uniocular exfoliative glaucoma the acetazolamide was increased from $125 \mathrm{mg}$ tds to $500 \mathrm{mg}$ bd 9 months after ALT. At that time the intraocular pressure in each eye was $11 \mathrm{mmHg}$. In the other case guttae epinephrine (adrenaline) $1 \%$ was added to both eyes despite the intraocular pressure in the lasered eye 
having fallen from a baseline mean of 23 to $17 \mathrm{mmHg}$ at six weeks after laser treatment. The intraocular pressure estimations following the increase in medication were also not included in the study. One patient who by our criteria would be classified as a failure and who received an addition of acetazolamide $375 \mathrm{mg}$ a day to his medical therapy was retained in the study because the increased medication was given secondary to poor control, and it was considered that this lack of control of intraocular pressure could not be discounted without biasing the study.

\section{Results}

Fifty-five eyes of 44 patients had laser trabeculoplasty in 1982; the mean age of the group was $70 \cdot 0$. Twentyone of 55 eyes $(38 \%)$ received only $180^{\circ}$ of argon laser trabeculoplasty rather than $360^{\circ}$ in two sessions separated by a few weeks.

Table 1 shows the effect of ALT on the mean intraocular pressure, the peak intraocular pressure, and the pressure irregularity of the diurnal curve.
This last was given by the standard deviation of the seven pressure readings from the mean measured over the 24-hour period. A composite reading for each patient consisting of all pressure recordings from one to six months after ALT and also a composite of the 9,12 , and 15 month readings are shown in the table, but the individual timed results are seen in Figs. 1 and 2 . A one-tailed paired $t$ test was performed, and the decrease in the mean IOP, the peak IOP, and pressure irregularity of the diurnal curve were all found to be significant $(p<0.0005)$.

Table 2 shows that $70 \%$ of patients could be classified as a success according to the above criteria, but of the subgroup with a baseline mean IOP of 21 $\mathrm{mmHg}$ or below only $30 \%$ qualified. A second method of classification for success, as defined by the peak intraocular pressure being $21 \mathrm{mmHg}$ or less following ALT, was considered which may be particularly appropriate for these patients with low pretreatment intraocular pressures.

In Table 3 the reduction in medical therapy following the laser treatment is shown. The total number of different medications taken (pilocarpine, adrenaline,

Table 1 Intraocular pressure and diurnal curve changes following laser treatment

\begin{tabular}{|c|c|c|c|c|c|}
\hline & Baseline & $\begin{array}{l}\text { Composite } \\
\text { 1-6 months }\end{array}$ & $\begin{array}{l}\text { Change from } \\
\text { baseline }\end{array}$ & $\begin{array}{l}\text { Composite } \\
9-15 \text { months } \\
\text { (52 eyes)t }\end{array}$ & $\begin{array}{l}\text { Change from } \\
\text { baseline }\end{array}$ \\
\hline Peak IOP mmHg (52 eyes $)^{*}$ & $30 \cdot 1$ & $21 \cdot 7$ & $8.4(28 \%)$ & - & \\
\hline $\begin{array}{l}\text { Pressure irregularity of } \\
\text { diurnal curve ( } 52 \text { eyes })^{*}\end{array}$ & 3.99 & $2 \cdot 62$ & $1 \cdot 37(35 \%)$ & & \\
\hline
\end{tabular}

*Three patients did not have repeat diurnal curves from 1 to 6 months after laser treatment and are not included. The average peak IOP for these three patients was $33 \mathrm{mmHg}$ and fell to $28 \mathrm{mmHg}(15 \%)$ by two weeks after ALT.

$\dagger$ Three patients had trabeculectomy before nine months after laser treatment.

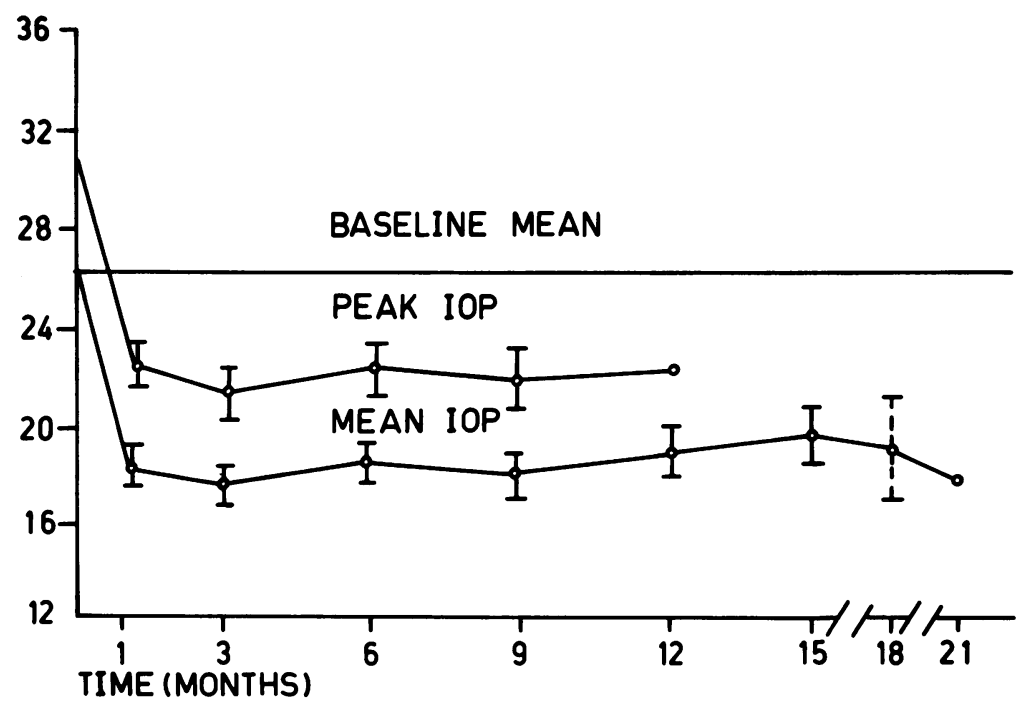

Fig. 1 Change in mean IOP and peak IOP with time. Bars show standard errors. 
Table 2 Success rates following laser treatment

\begin{tabular}{lll}
\hline & $\begin{array}{l}\text { Criteriafor success of } 20 \%+\text { fall in } \\
\text { IOP and IOP 21 mmHgorless }\end{array}$ & $\begin{array}{c}\text { Criteria for success of peak IOP } \\
<21 \text { mm } \mathrm{Hg} \text { for I-6 months }\end{array}$ \\
\hline $\begin{array}{l}\text { Total group } \\
\begin{array}{l}\text { Baseline mean IOP with } \\
\text { medical treatment }>21 \mathrm{mmHg}\end{array}\end{array}$ & $37 / 53^{*}(70 \%)$ \\
$\begin{array}{l}\text { Baseline mean IOP with } \\
\text { medical treatment }<21 \mathrm{mmHg}+(58 \%)\end{array}$ & $34 / 43(79 \%)$ \\
\hline
\end{tabular}

*Two patients classified as 'successful' but who had an increase in their medication not included (see 'Methods').

†One patient without diurnal curve measurements beyond two weeks after laser treatment not included.

Table 3 Reduction in medical treatment

\begin{tabular}{lc}
\hline Mean initial number of medications & $2 \cdot 00$ \\
Mean final number of medications & $1 \cdot 58$ \\
Number of patients off all medication & $8 / 55(15 \%)$ \\
Number with reduced number of medications & $14 / 55(25 \%)$ \\
\hline
\end{tabular}

timolol, and carbonic anhydrase inhibitors) was used to assess this, and the few cases of small alterations in strength and dosage of a particular agent were ignored. $15 \%$ of patients were able to stop all antiglaucoma medical treatment and a further $25 \%$ to reduce the number of their medications. These results are demonstrated graphically in Fig. 3.

Table 4 shows the early spike in intraocular pressure that can occur in the 24 hours following ALT. The best parameter to consider is perhaps a comparison with the diurnal curve peak intraocular pressure in the 24 hours before laser treatment, and it is of note that there were six cases $(7 \%)$ with an increase of $10 \mathrm{mmHg}$ or greater. Many previous authors have used the immediate pretreatment reading as a baseline or the starting mean and thus an increase of pressure above the diurnal curve mean has also been shown. In this case 32 eyes $(37 \%$ of laser treatments) had a pressure spike of $5 \mathrm{mmHg}$ or greater, of which $14(16 \%)$ were $10 \mathrm{mmHg}$ or more above baseline.

Table 5 shows that the total quantity of laser energy applied had little effect on success rate and also compares the results of those patients who received only $180^{\circ} \mathrm{ALT}$ with the remainder. The mean interval between laser treatments was three weeks.

As far as the failure cases are concerned, three proceeded to trabeculectomy three to six months after laser treatment. Another patient showed a poor response for 10 months after the first $180^{\circ}$ ALT at which stage treatment of the remaining half of the trabecular meshwork was performed. This patient subsequently did well for the next eight months.

Two of the cases were a success for a year at least, but then control was lost at 15 months and they could be classified as 'late failures.'

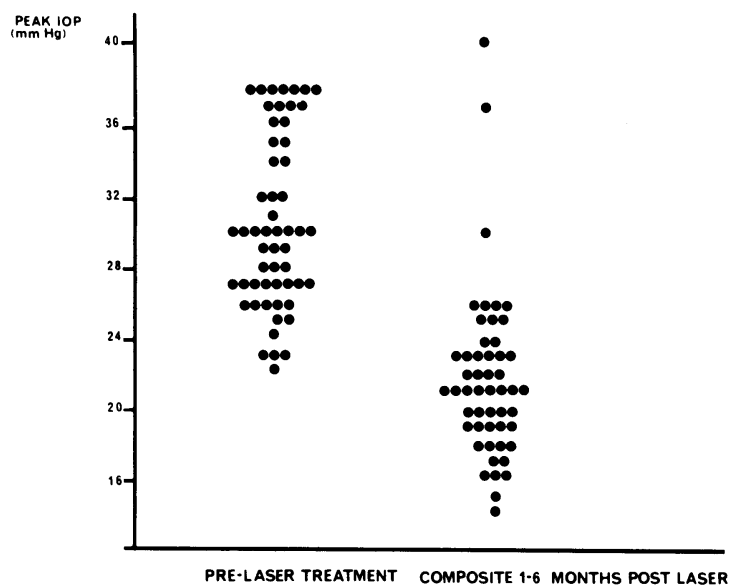

Fig. 2 Comparison of individual peak IOPs before and after $A L T$.

\section{Discussion}

In our treated group of 55 eyes (44 patients) with exfoliation syndrome glaucoma a fall in mean intraocular pressure at one year of $6.9 \mathrm{mmHg}(27 \%)$ was recorded following ALT, the figure being derived from a composite average for each patient, of ninemonth, 12-month, and 15-month readings. This fall

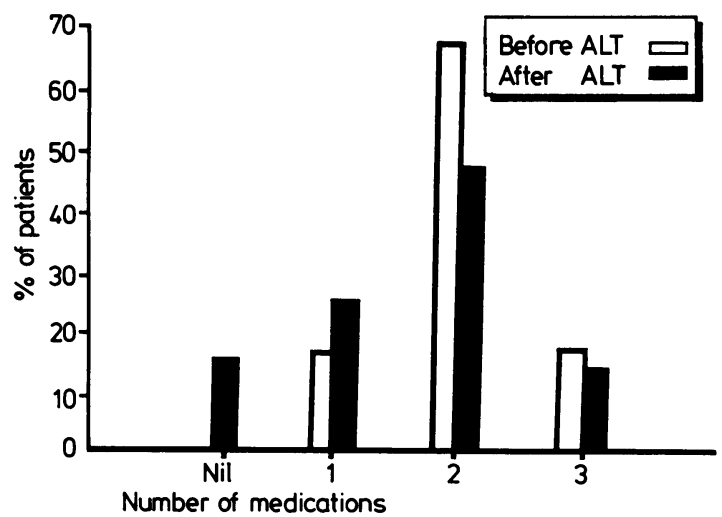

Fig. 3 Reduction in medication. 
Table 4 Early rise in peak IOP (first 24 hours)

\begin{tabular}{|c|c|c|c|c|}
\hline & \multicolumn{2}{|c|}{ Above baseline peak } & \multicolumn{2}{|c|}{ Above baseline mean } \\
\hline & Ist Laser & 2nd Laser & Ist Laser & 2nd Laser \\
\hline $\begin{array}{l}\text { Number of eyes with } \\
\text { early elevation of peak IOP }>5 \mathrm{~mm}\end{array}$ & 5 & 3 & 11 & 7 \\
\hline $\begin{array}{l}\text { Number of eyes with } \\
\text { early elevation of peak IOP }>10 \mathrm{~mm} \\
\text { Total }\end{array}$ & $\begin{array}{l}5 \\
10 / 55(18 \%)\end{array}$ & $\begin{array}{l}1 \\
4 / 32(13 \%)\end{array}$ & $\begin{array}{l}11 \\
22 / 55(40 \%)\end{array}$ & $\begin{array}{l}3 \\
10 / 32(31 \%)\end{array}$ \\
\hline
\end{tabular}

Table 5 Laser energyapplied

\begin{tabular}{lcr}
\hline & \multicolumn{1}{c}{ Success } & \multicolumn{1}{c}{ Failure } \\
\hline $180^{\circ}$ Laser only & $16 / 20(80 \%)$ & $4 / 20(20 \%)$ \\
$180^{\circ}$ Laser $\times 2$ & $21 / 33(64 \%)$ & $12 / 33(36 \%)$ \\
\hline$<3$ Joules & $4(80 \%)$ & $1(20 \%)$ \\
$3-4 \cdot 5$ Joules & $10(67 \%)$ & $5(33 \%)$ \\
$4 \cdot 5-6$ Joules & $8(62 \%)$ & $5(38 \%)$ \\
6+ Joules & $14(74 \%)$ & $5(26 \%)$ \\
\hline
\end{tabular}

Note: for one success case the power setting was not recorded.

in mean intraocular pressure was despite a reduction in medical treatment in $40 \%$ of the eyes subjected to laser treatment.

Analysis of the 24-hour diurnal curves showed a concomitant fall in peak intraocular pressure of $8.4 \mathrm{mmHg}(28 \%)$ and a reduction in the irregularity of the pressure curve of $34 \%$ between one and six months following laser treatment. Greenidge et al. ${ }^{6}$ have previously described a significant reduction in the mean peak pressure of $22 \%$ and in pressure fluctuation of $25 \%$ in diurnal curves of 25 patients with primary open angle glaucoma eight weeks after laser treatment. Here we see similar and if anything slightly greater improvements in the diurnal curves of exfoliation syndrome patients up to 12 months after ALT.

The average fall in mean intraocular pressure reached a maximum at three months of $8.0 \mathrm{mmHg}$ and then decreased a little, so that at one year it was $6.7 \mathrm{mmHg}$ and by 15 months $5.6 \mathrm{mmHg}$, though it did thereafter improve to $6.1 \mathrm{mmHg}$ by 18 months (Fig. 1). It is difficult to see whether there is a loss of effect of the laser treatment with time, as of course medical therapy was reduced or stopped in $40 \%$ of the eyes. Another factor confusing the issue is that the poor results of the three cases that proceeded to trabeculectomy are not included at the later time periods, which should theoretically lead to a marginal improvement in group results later on.

It can be seen from Table 5 that the amount of laser energy applied to the trabecular meshwork had no significant effect on the percentage of success of cases. The finding of slightly improved results of $80 \%$ success for the patients receiving $180^{\circ}$ laser compared with only $64 \%$ success for those receiving $2 \times 180^{\circ}$ laser is probably an artefact due to the fact that those patients who responded well did not have a second laser treatment. This impression is enhanced by the knowledge that patients receiving their second laser treatment within two weeks of the first-that is, before the effect of the first laser treatment could be fully determined-had an $80 \%$ success rate, like those receiving only $180^{\circ}$ of laser compared with $38 \%$ for those three weeks or longer between treatments.

At an individual level, by our criteria of a fall in intraocular pressure of at least $20 \%$ and in addition no two consecutive IOPs above $21 \mathrm{mmHg}, 70 \%$ of the treated group qualified so far as a success (mean follow-up 15 months). At one year this was even higher $(74 \%)$, but two patients who initially showed well controlled intraocular pressures subsequently 'failed' at 15 months. This finding of late failure among the exfoliation glaucoma patients has been documented by Pohjanpelto who described it in 10 out of his 93 initially successful exfoliation cases. ${ }^{2}$ Wilensky and Weinreb ${ }^{7}$ also described two cases of late failure, one of which was a patient with exfoliation glaucoma.

The 10 patients who, with their medical therapy, had starting mean intraocular pressures of $21 \mathrm{mmHg}$ or less showed only a $30 \%$ success rate by our criteria compared with a $79 \%$ success rate in those patients with a baseline intraocular pressure above $21 \mathrm{mmHg}$. In six out of the seven failures of this group classification was due to lack of the required $20 \%$ fall in intraocular pressure, the mean intraocular pressures remaining below $21 \mathrm{mmHg}$. It has been previously shown that the lower the intraocular pressure before laser the smaller is the decrease that can be expected both numerically and in percentage terms. ${ }^{38}$ It may therefore be unreasonable to apply the requirement of a $20 \%$ fall in intraocular pressure in this subgroup as a method of judging success. All 10 of these patients had elevated prelaser peak intraocular pressures (average $24.7 \mathrm{mmHg}$ ), and control of the peak pressure to $21 \mathrm{mmHg}$ or below may be a better criterion of success for this subgroup. In these terms six $(60 \%)$ could be graded 'successful.' 
As mentioned above, all patients received laser therapy to only $180^{\circ}$ of the meshwork at a time. In our study there were six cases of intraocular pressure rises of over $10 \mathrm{mmHg}$ in the immediate posttreatment hours, five of the six occurring after the first $180^{\circ}$ laser session. Indeed one patient had a rise in pressure to over $60 \mathrm{mmHg}$ from a starting peak intraocular pressure of $38 \mathrm{mmHg}$ and required osmotic agents to relieve symptoms. It may further be noted that none of the 22 eyes (18 patients) with phakic chronic simple glaucoma who received ALT at the same department by the same surgeons between January and December 1982 had an early IOP rise of $10 \mathrm{mmHg}$ or greater.

Weinreb et al. ${ }^{9}$ had only one of a mixed group of 20 patients treated with $180^{\circ}$ ALT to the anterior meshwork who showed a pressure rise of $10 \mathrm{mmHg}$. Thomas et al. ${ }^{3}$ reported three of 102 eyes treated with $2 \times 180^{\circ}$ ALT to the posterior meshwork, with pressure elevation of greater than $10 \mathrm{mmHg}$ above baseline. Neither of these papers compared pressure rises with peak baseline pressures. If a mean baseline pressure is considered, 14 cases $(16 \%)$ of a pressure spike of $10 \mathrm{mmHg}$ or greater were recorded, 11 of these occurring at the time of the first laser treatment. In view of these findings it would seem reasonable to suggest that exfoliation glaucoma patients should be even more closely monitored than others in the initial hours following ALT.

This study was partly funded by the Cripplegate Foundation and a Royal Society of Medicine travelling fellowship.

\section{References}

1 Pohjanpelto P. Argon laser treatment of the anterior chamber for increased intraocular pressure. Acta Ophthalmol (Kbh) 1981; 59: 211-20.

2 Pohjanpelto $P$. Late results of laser trabeculoplasty for increased intraocular pressure. Acta Ophthalmol (Kbh) 1983; 61: 9981008.

3 Thomas JV, Simmons RJ, Belcher CD. Argon laser trabeculoplasty in presurgical glaucoma patients. Ophthalmology (Rochester) 1982; 89: 187-97.

4 Olivius E, Thorburn W. Prognosis of glaucoma simplex and glaucoma capsulare. Acta Ophthalmol (Kbh) 1978; 56: 921-34.

5 Joannides TA, Katsourakis N, Velissaropoulos P. Glaucoma capsulare, 1 Kongr Europ Ges Ophth Athen, 1960. Ophthalmologica 1961; 142: 160-89.

6 Greenidge KC, Spaeth GL, Fiol-Silva Z. Effect of argon laser trabeculoplasty on the glaucomatous diurnal curve. Ophthalmology (Rochester) 1983; 90: 800-3.

7 Wilensky JT, Weinreb RN. Early and late failures of argon laser trabeculoplasty. Arch Ophthalmol 1983; 101: 895-7.

8 Schwartz AL, Kopelman J. Four year experience with argon laser trabecular surgery in uncontrolled open-angle glaucoma. Ophthalmology (Rochester) 1983; 90: 771-80.

9 Weinreb RM, Ruderman J, Juster R, Wilensky JT. Influence of the number of laser burns administered on the early results of argon laser trabeculoplasty. Am J Ophthalmol 1983; 95: 287-92. 